\title{
Consumer demand for low-alcohol wine in an Australian sample
}

\author{
This article was published in the following Dove Press journal: \\ International Journal of Wine Research \\ 28 March 2013 \\ Number of times this article has been viewed
}

\author{
Anthony J Saliba \\ Linda A Ovington \\ Carmen C Moran \\ Charles Sturt University, \\ Wagga Wagga, NSW, Australia
}

Correspondence: Anthony J Saliba School of Psychology, National Wine and Grape Industry Centre, Charles Sturt University, Locked Bag 588,

Wagga Wagga, NSW 2678, Australia

Tel +6I 269332000

Fax +6I 269332639

Email asaliba@csu.edu.au
Background: The aim of this paper is to inform wine producers and marketers of those in the population who are interested in low-alcohol wine by describing the results of an Australian survey.

Method: In the present study, 851 adult wine consumers completed an online questionnaire on their purchasing and consumption of wine, demographics, knowledge, and reasons for consuming wine. Reasons for consumption were defined using Brunner and Siegrist's validated model. Self-reported interest in low-alcohol wine was used to determine the likely maximum possible market size.

Results: The majority of respondents considered "low-alcohol wine" to contain around 3\%-8\% alcohol. Results indicated that those most likely to purchase low-alcohol wine were female and those who drink wine with food. Those who drank wine more frequently showed interest in wine sold in known-dose quantities, such as one standard drink. Reasons for preferring a low-alcohol wine included driving after drinking, to lessen the adverse effects of alcohol, and to consume more without the effects of a higher-alcohol wine. Finally, results pointed to the importance of taste as a driver of consumption.

Conclusion: This is the first study to define the opportunity market for low-alcohol wine in Australia agnostic to intervening variables, thus defines the likely upper limit. Further, we showed what consumers currently define as low alcohol. Both of these findings allow wine companies to make a decision on the profitability of the low-alcohol market in Australia.

Keywords: consumer demand, low alcohol, wine, consumer preference

\section{Background}

Through media attention and government programs, greater awareness on both the positive and the negative effects of alcohol on health has encouraged more individuals to adopt safer consumption patterns. In light to moderate amounts, wine has been shown to have some positive effects on health, namely protection from heart disease ${ }^{1}$ and type 2 diabetes $^{2}$ (for a review, see Yoo et $\mathrm{al}^{3}$ ). In opposition, the negative impact that high alcohol consumption and binge drinking has on health and social issues has led the World Health Organization to introduce a global strategy on reducing alcohol consumption. ${ }^{4}$ Some groups have suggested that even low levels of alcohol consumption could be harmful; thus, it is likely that consumers will continue to strive for convenient ways to minimize harm while enjoying the benefits that wine consumption affords.

Over recent years there has been a steady increase in alcohol content in wines produced in Australia and other countries such as South Africa and California in submit your manuscript $\mid$ www.dovepress.com

Dovepress

http://dx.doi.org//0.2147/IJWR.S41448
International Journal of Wine Research 2013:5 I-8

(C) 2013 Saliba et al, publisher and licensee Dove Medical Press Ltd. This is an Open Access article which permits unrestricted noncommercial use, provided the original work is properly cited. 
the US. The Australian Wine Research Institute reported an increase in mean alcohol content from $12.4 \%$ to $14.4 \%$ between 1984 and 2008 for red wines and an increase from $12.2 \%$ to $13.2 \%$ between 1984 and 2008 for white wine, then leveling to $12.9 \%$ in $2008 .{ }^{5}$ Factors contributing to rising levels of alcohol in wine include a hotter climate, healthier vines, leaving grapes on the vines longer, and more efficient yeasts. ${ }^{6}$ The implications of this are that in order to drink wine within a safe level of two standard drinks per day (ie, $20 \mathrm{~g}$ of alcohol), as recommended by the Australian National Health and Medical Research Council, ${ }^{7}$ a consumer purchasing wine with a higher alcohol content will need to drink less. That is, to stay within proposed healthy drinking levels, an individual could consume up to $200 \mathrm{~mL}$ of a $12 \%$ $\mathrm{v} / \mathrm{v}$ wine per day, whereas a glass of wine at $15 \% \mathrm{v} / \mathrm{v}$ would have to be reduced to a $150 \mathrm{~mL}$ glass.

The adoption of wine products with lower alcohol content is one solution to addressing this challenge, thus still allowing the enjoyment of wine; the corollary of this is that the wine industry may sell a greater volume of wine, thus helping industry profitability. Classifications of low-alcohol wines are differentially defined as dealcoholized $(<0.5 \% \mathrm{v} / \mathrm{v})$, low alcohol $(0.5 \%-1.2 \% \mathrm{v} / \mathrm{v})$, and reduced alcohol $(1.2 \%$ to $5.5 \%-6.5 \% \mathrm{v} / \mathrm{v})$, although this can vary between countries. ${ }^{8}$ As Australia is a member of the International Organization of Vine and Wine (OIV), beverages marketed as "alcohol-free wine" must contain "an alcoholic strength by volume below $0.5 \%$ vol" (resolution OIV-ECO 432-2012) and "partially alcoholised wine" to contain $0.5 \%$ or greater alcohol content but less than the applicable alcoholic strength of wine (resolution OIV-ECO 433-2012). In 2011, Food Standards Australia New Zealand ${ }^{9}$ approved an application from the Winemakers' Federation of Australia to amend the Australiaonly Standard 4.5.1: Wine Production Requirements in the Australia New Zealand Foods Standards Code, to reduce the minimum alcohol content for wine produced in Australia from $8 \%$ to $4.5 \% \mathrm{v} / \mathrm{v}$. A reason for approving the amendment was to support greater consistency with food standards in the European Union. Furthermore, it will allow Australian wine manufactures to export reduced-alcohol wine overseas, and provide Australian consumers with a more diverse range of low-alcohol wine products.

These changes have been possible due to the implementation of new techniques for removing alcohol while minimizing the impact on taste. ${ }^{9}$ Methods to lower alcohol content include, but are not restricted to, the use of enzyme technologies based on glucose oxidase, ${ }^{10}$ removing alcohol from wine through distillation ${ }^{11}$ and evaporation and low-alcohol-producing yeast ${ }^{12}$ (for detailed information, see Pickering ${ }^{8}$ ).

Research has revealed some consumer resistance in accepting low-alcohol wine, based on the principle that taste is affected when the alcohol is removed. For example, Masson et $\mathrm{al}^{13}$ conducted an experiment comparing evaluations of three lower-alcohol wines ( $9 \%$ white, rosé, and red) with a comparative standard wine (13\%). Participants evaluated the wines firstly under a blind tasting condition and then, after being made aware that certain wines were low in alcohol, were asked about their expectations of quality between them and the standard wines. Finally, participants tasted the wines and evaluated them again. The evaluations under both tasting conditions did not differ significantly. However, when asked about their expectations on perceived quality, expectations changed markedly ( $t=7.55, P<0.001$ for white, $t=5.91$, $P<0.001$ for rosé, and $t=8.07, P<0.001$ for red), suggesting that the low-alcohol cue impacts negatively on expected quality. These attitudes were probably formed due to the negative effects on taste that older techniques had on lowering alcohol in wine, though it is not our contention that current techniques are perfect in this regard.

A more recent study by Meillon et al ${ }^{14}$ using reverse osmosis to lower the alcohol content of wine indicated similar results for the taste of low-alcohol wine using less frequent wine drinkers; the same results were not found with regular drinkers or professionals in the wine industry. Using blind tasting of wines ranging from $9.6 \%$ to $13.6 \%$ alcohol, professionals reported not liking the low-alcohol varieties, noting a reduction in heat, mouthfeel, balance, and sweetness. Frequent, knowledgeable wine drinkers also reported a dislike for low-alcohol wine, whereas less frequent wine drinkers were more accepting. These results suggest that although improvements in manufacturing low-alcohol wine have occurred over recent years, more progress is required in order to capture the market of frequent wine drinkers.

In an ideal world, wine products could have the alcohol concentration manipulated with no impact on flavor. This is an engineering challenge but is not likely to be delivered in the moderate term. One of the enabling factors to facilitate this research is to define the size of the market that demands low-alcohol wine - if sufficiently large to allow profitable innovations, then the engineering research would surely follow. Further, as suggested by Meillon et al, ${ }^{15}$ some portion of the wine-drinking market may demand low-alcohol wine products, even with the current taste limitations. Further, current wine abstainers (but consumers of other alcoholic beverages) may be persuaded to consume wine of lower alcohol 
content. It is important to understand the size of the market that demands low-alcohol products, especially in countries where supply is currently exceeding demand.

In a research report commissioned by the German wine trade fair Prowein, Wine Intelligence (London, UK) gathered 1000 responses from regular wine drinkers in the US, China, Germany, and the UK. ${ }^{16}$ In the US, Germany, and the UK, around $22 \%$ preferred wine with $10.5 \%$ alcohol by volume or less. China's results were the most notable, with $91 \%$ desiring a wine with $8.5 \%-10 \%$; however, this work has not been peer reviewed. Research assessing demand for low-alcohol wine under different tax regimes in Australia using a discrete choice experiment found that $6 \%-8 \%$ of their respondents would adopt low-alcohol wine alternatives. ${ }^{17}$ This study defined low-alcohol wine as containing either $6 \%$ or $9 \%$ alcohol and investigated choice, whereby respondents were asked to recall their last wine purchase and indicate from a range of choices which wines they would substitute. The lowalcohol alternatives had specific prices and alcohol content; thus, decisions were influenced by those factors. Further, they examined only cask wine, as the focus of the study was on the influence of tax regimes on "bulk" wine. Mueller et al's ${ }^{17}$ approach is likely to provide a robust but conservative estimate of demand for low-alcohol wine sold in casks. The study did not measure what consumer's perceive low alcohol to represent, nor did the study measure the potential market size based on current consumer interest.

The present investigation aimed to define the alcohol level that consumers currently associate with low-alcohol wine; results will allow marketers to take a customercentered approach to product development. Further, by allowing consumers to define what low alcohol constitutes, results from the present study will not be restricted by any predefined alcohol level category that may or may not interest consumers. Such results will represent the opportunity market size, rather than the more conservative market size defined by Mueller et al. ${ }^{17}$ Again, this is important for wine marketers, as our approach would define the highest interest level.

The present study adopted the model validated by Brunner and Siegrist, ${ }^{1,18}$ including the variables most likely to be related to interest in low-alcohol wine, such as lifestyle and health concerns. Respondents were also given an opportunity to report in their own words why they would purchase lowalcohol wine. Results of the current study will assist in informing the wine industry of the opportunity market for low-alcohol wine and, more specifically, the characteristics of the consumer and situations in which a low-alcohol wine would be likely to be purchased.

\section{Method}

This study was approved by the Charles Sturt University Ethics in Human Research Committee, Wagga Wagga, NSW, Australia, and conforms to the provisions of the Declaration of Helsinki.

\section{Participants and procedure}

A total of 851 adult participants in Australia were recruited through the Australian office of a market research database, with responses to the survey completed online in January 2012. The survey used stratified random sampling with affixation proportional to gender, and was geographically balanced across Australia so as to include representations from each state, consistent with known population levels (see Table 1). To participate, respondents were required to be 18 years or older and consume wine. The resultant sample comprised $49.6 \%$ males and $50.4 \%$ females, ranging in age from 18 to 93 years (mean $[\mathrm{M}]=46.4$ years, standard deviation $[\mathrm{SD}]=16.1$ years). Years of experience of drinking wine was diverse, with a range of 62 years and a median of 20 years. More information on demographics is provided in the Results section.

The survey included questions on demographics, wine, and general alcohol consumption: frequency (never to every day) and number of standard drinks consumed in this time of wine, beer, spirits, and ready-to-drinks. Also included were wine purchasing behaviors: reasons for purchasing (to consume at home, away from home, celebration, cellaring, gift), monthly amount spent and consumed (bottles and casks), and amount spent on individual styles (red, white, sparkling, fortified, and other). Scales from Brunner and Siegrist's ${ }^{1}$ questionnaire on lifestyle determinants of wine consumption were used to measure involvement and lifestyle, respectively. These items were scored on a 6-point Likert scale from 1: completely disagree to 6 : completely agree. Table 2 contains an item example, number of items, and Cronbach's $\alpha$ for the involvement subscale (knowledge) and the eleven subscale

Table I Respondent numbers and percentages per Australian state and territory $(n=85$ I $)$

\begin{tabular}{lll}
\hline State & $\mathbf{n}$ & $\%$ \\
\hline New South Wales & 280 & 32.9 \\
Victoria & 225 & 26.5 \\
Queensland & 147 & 17.2 \\
Western Australia & 98 & 11.5 \\
South Australia & 72 & 8.5 \\
Tasmania & 18 & 2.1 \\
Australian Capital Territory & 9 & 1.1 \\
Northern Territory & 2 & 0.2 \\
\hline
\end{tabular}


Table 2 Involvement and lifestyle items, including item example, number of items, and reliability scores

\begin{tabular}{|c|c|c|c|}
\hline Dimension & Example of an item & $\begin{array}{l}\text { No of } \\
\text { items }\end{array}$ & Cronbach's $\alpha$ \\
\hline \multicolumn{4}{|l|}{ Involvement } \\
\hline Knowledge & $\begin{array}{l}\text { I have a good general } \\
\text { knowledge about wine }\end{array}$ & 9 & 0.92 \\
\hline \multicolumn{4}{|l|}{ Lifestyle } \\
\hline Self-expression & $\begin{array}{l}\text { I drink wine to } \\
\text { be distinctive }\end{array}$ & 8 & 0.87 \\
\hline Recreation & $\begin{array}{l}\text { I drink wine when } \\
\text { I feel lonely }\end{array}$ & 6 & 0.82 \\
\hline Sociability & $\begin{array}{l}\text { I drink wine to } \\
\text { be sociable }\end{array}$ & 7 & 0.86 \\
\hline Health & $\begin{array}{l}\text { I drink wine for } \\
\text { health-related aspects }\end{array}$ & 6 & 0.79 \\
\hline Style & I drink wine to be stylish & 5 & 0.82 \\
\hline Food & $\begin{array}{l}\text { I drink wine to enhance } \\
\text { the taste of food }\end{array}$ & 3 & 0.79 \\
\hline Pleasure & I drink wine for pleasure & 3 & 0.76 \\
\hline Tradition & I drink wine for ritual & 3 & 0.72 \\
\hline Fun & I drink wine to have fun & 4 & 0.73 \\
\hline $\begin{array}{l}\text { Intellectual } \\
\text { challenge }\end{array}$ & $\begin{array}{l}\text { I drink wine to try } \\
\text { something new }\end{array}$ & 2 & 0.78 \\
\hline
\end{tabular}

dimensions for lifestyle. The Cronbach's $\alpha$ for each subscale was satisfactory, demonstrating acceptable internal consistency for each of the scales.

Five additional questions asked respondents the extent to which they agreed with the statements: (1) "If taste is the same, I am ready to choose wine with less alcohol in it,"19 (2) "I am concerned about the level of alcohol in wine compared with beer," (3) "I find it hard to figure out what a 'standard drink' is for wine compared with beer," (4) "It would be good if wine were sold in small 'standard drink' serves, like beer," and (5) "I am interested in 'low-alcohol' wine products." The response range was from 1: completely disagree to 6: completely agree. A final qualitative question asked respondents to complete the sentence: "I am interested in 'low-alcohol' wine products because ..." Respondents also had the option to choose "I am not interested in low-alcohol wine products."

\section{Results}

An $\alpha$ level of 0.05 was adopted for interpretation of significance for all statistical tests. All analyses were conducted on PASW (previously known as SPSS), version 17 (SPSS, Inc, Chicago, IL). Seven respondents were eliminated due to extreme scores, leaving $n=844$. Means, confidence intervals, $\mathrm{SD}$, and reliabilities for the involvement and lifestyle scales are reported in Table 3.

Table 4 characterizes frequency of wine consumption, purchasing, perceptions of the term "low alcohol," and
Table 3 Means, confidence intervals $(\mathrm{Cl})$, standard deviations (SD), and reliabilities for involvement and lifestyle scales

\begin{tabular}{llll}
\hline & Mean $(\mathbf{9 5} \% \mathbf{C I})$ & SD & Cronbach's $\alpha$ \\
\hline Knowledge & $22.99(22.56-23.33)$ & 9.79 & 0.94 \\
Self-expression & $16.47(16.17-16.77)$ & 8.63 & 0.95 \\
Recreation & $16.33(16.12-16.55)$ & 6.26 & 0.86 \\
Sociability & $22.45(22.20-22.70)$ & 7.32 & 0.90 \\
Health & $16.05(15.83-16.27)$ & 6.33 & 0.89 \\
Style & $11.94(11.74-12.14)$ & 5.78 & 0.92 \\
Food & $11.69(11.57-11.8 I)$ & 3.48 & 0.86 \\
Pleasure & $13.86(13.76-13.96)$ & 2.91 & 0.71 \\
Tradition & $6.31(6.19-6.43)$ & 3.43 & 0.86 \\
Fun & $15.87(15.73-16.01)$ & 4.11 & 0.79 \\
Intellectual challenge & $5.79(5.71-5.87)$ & 2.40 & 0.75 \\
\hline
\end{tabular}

percentage of alcohol in wine normally consumed. Of those who identified themselves as the main buyer, $53.3 \%$ were men and $46.7 \%$ were women, and for those who identified themselves as the main consumer, $50.4 \%$ were men and $49.6 \%$ were women. Almost $70 \%$ of respondents considered lowalcohol wine to be between $3 \%$ and $8 \%$. Within this range, wine tends to lose perceived viscosity and weight $(0 \%-10 \%$ alcohol $\mathrm{v} / \mathrm{v}$ ), as reported by Pickering et al. ${ }^{20}$ Twenty-one percent of participants were not aware of the percentage of

Table 4 Wine consumption, purchasing, and perception of the term "low alcohol"

\begin{tabular}{lll}
\hline & $\mathbf{n}$ & $\%$ \\
\hline Wine consumption frequency & & \\
Every day & 65 & 7.7 \\
Several times a week & 293 & 34.7 \\
Once a week & 167 & 19.8 \\
Once a fortnight & 90 & 10.7 \\
Once a month & 115 & 13.6 \\
Once every 2 months & 114 & 13.5 \\
Buying and consumption & & \\
Main buyer & 659 & 78.1 \\
Main consumer & 283 & 33.5 \\
Neither main buyer nor consumer & 121 & 14.3 \\
What is considered low alcohol? & & \\
II\%-I2\% & 22 & 2.6 \\
$9 \%-10 \%$ & 67 & 7.9 \\
$7 \%-8 \%$ & 135 & 16.0 \\
$5 \%-6 \%$ & 221 & 26.2 \\
$3 \%-4 \%$ & 227 & 26.9 \\
I\%-2\% & 145 & 17.2 \\
$0 \%$ & 27 & 3.2 \\
Percentage of alcohol in wine usually consumed & \\
$\geq 15 \%$ & 39 & 4.6 \\
I3\%-I4\% & 194 & 23.0 \\
II\%-I2\% & 225 & 26.7 \\
$9 \%-10 \%$ & 120 & 14.2 \\
$<9 \%$ & 89 & 10.5 \\
Don't know & 177 & 21.0 \\
\hline
\end{tabular}


alcohol in the wine they normally consumed, which gives rise to the prospect that these individuals may be consuming more alcohol than they realize.

A one-way analysis of variance (ANOVA) was used to compare male $(\mathrm{M}=3.07, \mathrm{SD}=1.57)$ versus female $(\mathrm{M}=3.61$, $\mathrm{SD}=1.61)$ interest in low-alcohol wine. The ANOVA was statistically significant, with females demonstrating greater interest in low-alcohol wine than men, $F(1,842)=24.17$, $P<0.001, \mathrm{Eta}^{2}=0.039$.

To estimate the proportion of variance for interest in low-alcohol wine that can be accounted for by reasons for drinking wine (involvement and lifestyle items), a linear multiple regression analysis (MRA) was performed. Statistical assumptions were all met, indicating that multicollinearity would not interfere with the outcome of the MRA. Mahalanobis distance did not exceed the critical $\chi^{2}$ for $d f=11$ (at $\alpha=0.001$ ) of 31.3. This indicates that no outliers are artificially altering the regression slope. In combination, involvement and lifestyle items accounted for a significant $5 \%$ of the variability in interest in low-alcohol wine, $R^{2}=0.05$, adjusted $R^{2}=0.033$, $F(11,832)=3.61, P<0.001$. Unstandardized $(\mathrm{B})$, standard error (SE B), and standardized ( $\beta$ ) regression coefficients are reported in Table 5.

Similarly, MRA was used to estimate the proportion of variance associated with frequency of consumption of wine that can be accounted for by: (1) preference for low-alcohol wine if taste were the same, (2) concern over level of alcohol in wine compared with beer, (3) level of difficulty in understanding what a "standard drink" is for wine compared with beer, (4) desire for wine to be sold in standard drink serves like beer, and (5) general interest in low-alcohol wine products. Assumptions of normality, linearity, and homoscedasticity

Table 5 Summary of multiple regression analysis for variables predicting interest in low-alcohol wine

\begin{tabular}{llll}
\hline Variable & B & SE B & $\beta$ \\
\hline Constant & 3.05 & 0.30 & \\
Involvement (knowledge) & -0.01 & 0.01 & -0.05 \\
Self-expression & 0.00 & 0.01 & 0.02 \\
Recreation & -0.01 & 0.01 & -0.04 \\
Sociability & -0.01 & 0.01 & -0.04 \\
Health & -0.01 & 0.01 & 0.03 \\
Style & 0.02 & 0.02 & 0.06 \\
Food & 0.09 & 0.02 & $0.19 * *$ \\
Pleasure & -0.05 & 0.03 & $-0.07^{*}$ \\
Tradition & 0.03 & 0.02 & 0.07 \\
Fun & -0.01 & 0.02 & -0.01 \\
Intellectual challenge & -0.00 & 0.03 & -0.00 \\
\hline
\end{tabular}

Notes: $R^{2}=0.05(P>0.05)$. $* P<0.05 ; * * P<0.001$.

Abbreviations: $B$, unstandardized; SE B, standard error; $\beta$, standardized. of residuals were met. Mahalanobis distance did not exceed the critical $\chi^{2}$ for $d f=5$ (at $\alpha=0.001$ ) of 20.08. In combination, the aforementioned items accounted for a significant $3 \%$ of the variability in frequency of consumption of wine, $R^{2}=0.03$, adjusted $R^{2}=0.021, F(5,838)=4.69, P<0.001$. Unstandardized (B), standard error (SE B), and standardized $(\beta)$ regression coefficients are reported in Table 6.

In order to explore the reasons for, and situations in which, individuals may prefer to purchase a low-alcohol wine over a higher-alcohol wine, the sentence "I am interested in 'low-alcohol' wine products because ..." was used for respondents to complete in their own words. Of the 844 participants, 322 participants (38\%) chose the option "I am not interested in low-alcohol wine," with the remaining 522 giving reasons; responses are shown in Table 7. Being able to drive after drinking was the main reason respondents offered. Health reasons included weight loss, having intolerance for alcohol, not being able to consume alcohol due to medication, and preventing alcohol-related diseases (liver and brain damage). Reducing the effects of alcohol was also of high concern for many respondents, such as the feeling of intoxication, feeling "out of control," and hangovers.

Table 8 shows relative acceptance of low-alcohol wine in the current Australian study compared with France, the UK, and Germany, as reported by d'Hauteville. ${ }^{19}$ Within the same samples, Table 9 shows preference for low-alcohol wine, with taste being equal. The percentage figures for the Australian, French, and German samples were obtained from the Likert scales graded from 1 to 6 and for the UK sample 1 to 5 . Therefore, grades $1-2=$ reject/disagree, grades $3-4$ ( 3 only for UK sample $)=$ neither reject nor accept, and grades $4-5=$ accept/agree. For the current study, a $t$-test was performed to investigate whether the difference between general interest in low-alcohol wine $(\mathrm{M}=3.34, \mathrm{SD}=1.61)$

Table 6 Summary of multiple regression analysis for variables predicting frequency of wine consumption

\begin{tabular}{llll}
\hline Variable & B & SE B & $\beta$ \\
\hline Constant & 2.80 & 0.17 & \\
$\begin{array}{l}\text { Preference for low-alcohol wine } \\
\text { if taste is the same }\end{array}$ & 0.07 & 0.05 & 0.07 \\
$\begin{array}{l}\text { Concern over the level of alcohol } \\
\text { in wine compared with beer }\end{array}$ & -0.11 & 0.05 & -0.1 I* $^{*}$ \\
$\begin{array}{l}\text { Difficulty understanding what a "standard } \\
\text { drink" is for wine compared with beer }\end{array}$ & 0.06 & 0.04 & 0.05 \\
$\begin{array}{l}\text { Desire for wine to be sold in } \\
\text { "standard drink" serves, like beer }\end{array}$ & 0.14 & 0.04 & $0.15^{* *}$ \\
\begin{tabular}{l} 
General interest in low-alcohol wine \\
\hline
\end{tabular} & -0.04 & 0.05 & -0.04 \\
\hline
\end{tabular}

Notes: $R^{2}=0.03(P>0.05)$. *P $<0.05 ; * * P<0.001$.

Abbreviations: $B$, unstandardized; SE B, standard error; $\beta$, standardized. 
Table 7 Qualitative answers to reasons given for interest in lowalcohol wine

\begin{tabular}{ll}
\hline Reason & $\begin{array}{l}\text { Number of } \\
\text { responses (\%) }\end{array}$ \\
\hline I am interested in low alcohol because (n = 522) & \\
Driving & $101(19 \%)$ \\
Health & $84(16 \%)$ \\
Lessen effects of alcohol & $83(16 \%)$ \\
Lower alcohol consumption (but still enjoy wine) & $63(12 \%)$ \\
Able to drink more without the effects of alcohol & $56(11 \%)$ \\
Another option & $26(5 \%)$ \\
Enjoy the taste of wine, alcohol unnecessary & $13(2 \%)$ \\
Safer & $12(2 \%)$ \\
Possibly cheaper & $7(1 \%)$ \\
Breastfeeding & $3(0.5 \%)$ \\
\hline
\end{tabular}

and interest in low-alcohol wine if taste is equal $(\mathrm{M}=3.95$, $\mathrm{SD}=1.56$ ) were significantly different. The difference was significant, $t(843)=12.84, P<0.001, d=0.38$, suggesting that the cue "if taste is the same" increases people's interest in low-alcohol wine products.

\section{Discussion}

In the present study, almost $70 \%$ of respondents perceived that a low-alcohol wine would contain around 3\%-8\% alcohol. Twenty-one percent of respondents were not aware of the alcohol percentage in the wine they normally consumed. Women were statistically more interested in purchasing lowalcohol wines compared with men, whereas those who enjoy wine with food were also more likely to be interested in lowalcohol wines. Alternatively, those who drink for pleasure were least likely to be interested in low-alcohol wines. Frequent wine drinkers showed interest in purchasing wine in "standard drink" serves, similar to how beer is currently sold, and were least concerned over the level of alcohol in wine compared with beer. Other reasons for preferring a low-alcohol wine to a higher-alcohol wine included occasions when one would like to drive after drinking alcohol, for health, to lessen the effects of alcohol, to lower overall alcohol consumption, or to enjoy more wine without the side effects of alcohol, all

Table 8 Relative interest in low alcohol wine in four countries, Australia, France, UK, Germany (\%)

\begin{tabular}{lllll}
\hline & Australia & France & UK & Germany \\
\hline Reject & 46.6 & 61.1 & 54.2 & 31.4 \\
Neither reject nor accept & 37.7 & 21.0 & 19.2 & 42.4 \\
Accept & 15.8 & 12.4 & 26.7 & 19.5 \\
No opinion & 0.0 & 4.7 & 0.0 & 7.7 \\
Respondents (n) & 844 & 105 & 120 & 119 \\
\hline
\end{tabular}

Notes: Australian statistics from current study; France, the UK, and Germany statistics from d'Hauteville. ${ }^{19}$
Table 9 Readiness to choose wine with a low alcohol content if taste is the same as a standard wine in four countries, Australia, France, UK and Germany (\%)

\begin{tabular}{lllll}
\hline & Australia & France & UK & Germany \\
\hline Disagree & 19.5 & 46.7 & 47.5 & 16.9 \\
Neither agree nor disagree & 40.0 & 19.1 & 28.3 & 17.8 \\
Agree & 40.4 & 33.2 & 24.2 & 65.2 \\
No opinion & 0.0 & 1.0 & 0.0 & 1.1 \\
Respondents (n) & 844 & 105 & 120 & 119 \\
\hline Note: Australian statistics from current study; France, UK and Germany statistics
\end{tabular}
from d'Hauteville. ${ }^{19}$

categories that shared some commonality. Finally, relative acceptance of low-alcohol wine was $16 \%$ in our study, rising to a significant $40 \%$ if taste were the same as standard wine products. This may suggest that these respondents perceived low-alcohol wine as being inferior to regular wine, as was found by Masson et al. ${ }^{13}$ Alternativley, if low-alcohol wine were to taste the same as regular wine, there would be greater acceptance. Clearly, even where low-alcohol products offer a taste-competitive alternative, there is a marketing challenge to convince consumers of that fact.

Our results differ from those reported by Mueller et al. ${ }^{17}$ Overall, the results in the present study are more positive as to the prospects of low-alcohol wine in Australia. Whereas we report relative acceptance of $16 \%$ (rising to $40 \%$ if taste were the same as standard wine), Mueller et a ${ }^{17}$ report $6 \%-8 \%$ interest. The two studies differ substantially, so it is difficult to determine exactly why the differences occurred. Firstly, our study measured self-reported interest in low-alcohol wine, therefore we have reported the upper range of market opportunity, whereas Mueller et $\mathrm{al}^{17}$ defined the more conservative purchase-choice substitution effect derived from differences in price based on different tax regimes. Secondly, we have not defined "low alcohol," price, or other variables, such that our study reports market opportunity agnostic to these variables.

A majority of low-alcohol wine consumers have reportedly been women..$^{21}$ The findings of the current study indicate that women are indeed more interested in low-alcohol wine than men, although the effect size was relatively small, which suggests that men should not be completely ruled out as possible customers in the future. This may be especially so for those who drink wine with food. An argument put forward for producing wine with less alcohol by Meillon et $\mathrm{al}^{14}$ was that "wine consumers often state that high-alcohol wines are too heavy to serve with food." In support of this statement, the findings in the present study indicate that those who enjoy wine with food were also interested in low-alcohol wine. 
Although it was found that frequent wine drinkers were not concerned over the level of alcohol in wine compared with beer, interest in purchasing wine in "standard drink" bottles in the same way beer is served was found. This may be explained by the finding that twice as many men than women consumed wine every day, suggesting that although men are less likely to be interested in low-alcohol wine, control over consumption of alcohol can be monitored by number of standard drinks consumed in the same way as beer. This question was explorative in nature with no previous research investigating this concept. Thus, further exploration into the possible production of standard drink size wine bottles may be warranted.

In the current study, respondents were provided with the opportunity to give reasons in their own words as to why they may be interested in low-alcohol wine. The majority of responses were concerned with being able to drive after drinking. Empirical evidence has shown that television campaigns in Australia targeting drink driving are effective in reducing alcohol-related accidents and driving under the influence. ${ }^{22}$ The present study appears to support the positive effect of these messages, and as no question regarding drinking and driving was asked, it is unlikely this result is bias. This argument also holds for the next most popular response for reasons to purchase low-alcohol wine: health. A recent review of 21 research articles on community support for regulations of alcohol across Australia between 1998 and 2009 showed that two-thirds of people support the introduction of health warnings on alcohol. ${ }^{23}$ In another recent study, however, almost $25 \%$ of respondents either agreed or strongly agreed that consuming wine has health benefits. ${ }^{24}$ These two findings appear in conflict but can be explained by further results from Saliba and Moran ${ }^{24}$ that showed that people who thought that wine had health benefits did not consume higher quantities. Unlike the "eat more if it is healthy" phenomena reported for some food products, ${ }^{25}$ it appears that wine consumers understand that the presence of alcohol warrants wine to be consumed in moderation. Other reasons identified for the option to purchase low-alcohol wine in the present study were for those who could not drink alcohol due to the medication they are taking or because of sensitivity to alcohol. Many respondents reported the enjoyment of drinking wine but did not like the feeling of being drunk, which is also related to what others reported, namely being able to drink more wine without the effects of higher-alcohol products. Several participants also stated wanting to reduce their alcohol consumption while still being able to enjoy wine.
Relative interest in low-alcohol wine in Australia was comparable with the findings in Germany. If low-alcohol wine were to taste similar to "standard" wine, fewer Australians than Germans expressed interest. Although similar findings between the two countries were found for "disagree," more Australians than Germans were "neutral" (neither agree nor disagree). This suggests that although few Australians overtly reject low-alcohol wine if taste is the same, there is still some way to go before they accept it. Comparisons between the current Australian study with France, the UK, and Germany on relative interest in low-alcohol wine products, and preference for low-alcohol wine given that taste is equal, are difficult. Data from d'Hauteville's ${ }^{19}$ study were collected 18 years ago; thus, it is not clear whether the differences in the current study are due to changes in time or locality. Moreover, a recent independent retailer report by Wine Intelligence found an increasing demand in the UK for wines below $12 \%$ alcohol by volume. ${ }^{26}$ More research is needed to determine whether demand for low-alcohol wine in Australia compares with other countries, but it appears that moderate demand for lowalcohol wine currently exists in Australia, and that demand would rise substantially if consumers thought that taste would not be adversely affected.

A factor not considered in the current study is involvement. Previous research has shown that wine consumers with low involvement are less likely to purchase wine with screw cap lids, whereas consumers with high involvement avoid "green wines" due to the perception of these products being of lower quality, regardless of actual quality. ${ }^{27}$ It is possible that wine consumers with high involvement perceive lowalcohol wine as inferior, although this is speculative. Future research should consider involvement as a factor in purchase intention of low-alcohol wine.

\section{Conclusion}

As argued by Levitt, ${ }^{28}$ a successful industry is built on orienting toward what customers want. As drink-driving messages and health warnings on consuming large and even small amounts of alcohol have their impact on the population, the needs of consumers will inevitably change. Even though the proposed increase of alcohol tax, particularly on beverages with high alcohol content, ${ }^{7}$ has met with opposition by the wine industry, ${ }^{29}$ it will inevitably have its impact also. New innovations that improve on the taste of low-alcohol wine may be the answer to continuing productivity in a changing market, as this study has demonstrated that a moderate portion of the Australian domestic market demands lowalcohol products now, increasing if taste can be maintained. 
The challenges for wine marketers are substantial; however, this study suggests that the market size, should these challenges be overcome, will be of sufficient size to interest many wine businesses.

\section{Acknowledgment}

This work was conducted through a grant provided by the Faculty of Arts Research Office at Charles Sturt University, Wagga Wagga, NSW, Australia.

\section{Disclosure}

The authors report no conflicts of interest in this work.

\section{References}

1. Renaud S, de Lorgeril M. Wine, alcohol, platelets, and the French paradox for coronary heart disease. Lancet. 1992;339(8808): $1523-1526$.

2. Klatsky AL. Alcohol and cardiovascular diseases. Expert Rev of Cardiovasc Ther. 2009;7(5):499-506.

3. Yoo YJ, Saliba AJ, Prenzler PD. Should red wine be considered a functional food? Comp Rev in Food Sci and Food Safety. 2010;9(5): $530-551$.

4. World Health Organization. Global Strategy to Reduce The Harmful Use of Alcohol. In: Organisation WH, editor. Geneva, Switzerland: World Health Organization; 2010.

5. Godden P, Muhlack R. Trends in the composition of Australian wine. Aust NZ Grapegrow Winemak. 2010(558):47-61.

6. Conibear H. Rising alcohol levels in wine: is this a cause for concern? AIM Digest. 2008;18(4):1-3.

7. National Health Medical Research Council. Australian guidelines to reduce health risks from drinking alcohol. Canberra, Australia: National Health and Medical Research Council; 2009.

8. Pickering GJ. Low-and reduced-alcohol wine: a review. $J$ Wine Res. 2000;11(2):129-144.

9. Food Standards Australia New Zealand. Application A1026 minimum alcohol content for wine explanatory statement. In: Food Standards Australia New Zealand, ed2011.

10. Pickering G, Heatherbell D, Barnes M. Optimising glucose conversion in the production of reduced alcohol wine using glucose oxidase. Food Res Int. 1998;31(10):685-692.

11. Aguera E, Bes M, Roy A, Camarasa C, Sablayrolles JM. Partial removal of ethanol during fermentation to obtain reduced-alcohol wines. Am J Enol Vitic. 2010;61(1):53.
12. Ehsani M, Fernandez MR, Biosca JA, Julien A, Dequin S. Engineering of 2, 3-butanediol dehydrogenase to reduce acetoin formation by glycerol-overproducing, low-alcohol Saccharomyces cerevisiae. Appl EnviroMicrobiol. 2009;75(10):3196.

13. Masson J, Aurier P, d'Hauteville F. Effects of non-sensory cues on perceived quality: The case of low-alcohol wine. Int J Wine Busin Res. 2008;20(3):215-229.

14. Meillon S, Dugas V, Urbano C, Schlich P. Preference and acceptability of partially dealcoholized white and red wines by consumers and professionals. Am J Enol Vitic. 2010;61(1):42-52.

15. Meillon S, Viala D, Medel M, Urbano C, Guillot G, Schlich P. Impact of partial alcohol reduction in Syrah wine on perceived complexity and temporality of sensations and link with preference. Food Qual Prefer. 2010;21(7):732-740.

16. Lechmere A. Consumers across three continents prefer lower alcohol wines: Prowein. Decanter. West Sussex, UK: PC Media; 2012.

17. Mueller S, Lockshin L, Louviere J. Alcohol in moderation: Market potential for low alcohol wine before and after excise tax. 6th AWBR International Conference. Talence, France: Bordeaux Management School; 2011.

18. Brunner TA, Siegrist M. A consumer-oriented segmentation study in the Swiss wine market. Br Food J. 2011;113(3):353-373.

19. d'Hauteville F. Consumer acceptance of low alcohol wines. Int J Wine Market. 1994;6(1):35-48.

20. Pickering GJ, Heatherbell D, Vanhanen L, Barnes M. The effect of ethanol concentration on the temporal perception of viscosity and density in white wine. Am J Enol Vitic. 1998;49(3):306-318.

21. Howley M, Young N. Low-alcohol wines: The consumer's choice? Int J Wine Market. 1992;4(3):45-56.

22. Tay R. Mass media campaigns reduce the incidence of drinking and driving. Evidence-Based Healthcare and Public Health. 2005;9(1): 26-29.

23. Tobin C, Moodie AR, Livingstone C. A review of public opinion towards alcohol controls in Australia. BMC Public Health. 2011;11(1):58.

24. Saliba AJ, Moran CC. The influence of perceived healthiness on wine consumption patterns. Food Qual Prefer. 2010;21(7):692-696.

25. Provencher V, Polivy J, Herman P. Perceived healthiness of food: If it's healthy, you can eat more! Appetite. 2009;52:340-344.

26. Halstead R, Fong M. UK independent wine sector reports growing sales at higher price points and greater emphasis on lower alcohol. London, UK: Wine Intelligence; 2012.

27. Barber N, Ismail J, Dodd T. Purchase attributes of wine consumers with low involvement. Journal of Food Products Marketing. 2007;14(1): 69-86.

28. Levitt T. Marketing myopia. Harvard Business Review. 2004;82(7/8): 138-149.

29. Richardson D, Denniss R. The Australian wine tax regime. Canberra, Australia: The Australia Institute; 2011.
International Journal of Wine Research

\section{Publish your work in this journal}

The International Journal of Wine Research is an international, peer-reviewed open-access, online journal focusing on all scientific aspects of wine, including: vine growing; wine elaboration; human interaction with wine; and health aspects of wine. The journal provides an open access platform for the reporting

\section{Dovepress}

of evidence based studies on these topics. The manuscript management system is completely online and includes a very quick and fair peer-review system, which is all easy to use. Visit http://www.dovepress.com/testimonials.php to read real quotes from some of our published authors. 